\title{
VISUALIZING THE FUTURE OF EVENT STUDIES
}

\author{
TIJANA RAKIĆ* AND TOMAS PERNECKY† \\ *School of Sport and Service Management, University of Brighton, Eastbourne, UK \\ †School of Hospitality and Tourism, Faculty of Culture and Society, Auckland University of Technology, \\ Auckland, New Zealand
}

\begin{abstract}
In our hope to "visualize the future of event studies," this article offers practical pointers for event scholars who are interested in visual methods within their research and pedagogic practice. Prior to exploring the reasons for using visual methods as legitimate tools, this article provides an initial overview of both the history and the range of visual methods used across the social sciences, which in turn serves to contextualize visual event studies within the broader tradition of visual studies. The practicalities of designing and conducting visual research projects as well as the possible ethical dilemmas and the potential to reach wider audiences are also discussed.
\end{abstract}

\section{Key words: Visual event studies; Visual methodologies; Visual data analysis; Visual research outputs; Visual ethics;}

Introduction

Visual methods are a fairly new addition to the repertoire of events research, as marked by this Special Issue, which is the first to be dedicated to this topic. In a domain of study that is inherently multisensory and thus also visual, it is apt to delve deeper into, and examine, the ways in which event studies can become more visual. There are a number of decisions and challenges facing researchersin particular novice researchers - and so, it is important to address these more systematically as a way of building a strong and better-informed visual culture in the field. This article is best viewed as a continuation of the Introduction (Pernecky \& Rakić, 2019) in which we tackled the broader conceptual, philosophical, and theoretical matters. What follows is a brief overview of the key developments in the social sciences-addressed mainly to help events scholars and novice researchers to understand some of the historical tensions. The article then moves to outlining the practical elements of visual research, including the design of research projects; the collection of visual material and analysis; the creation of visual material for research purposes; elicitation techniques; and similar alternatives such as "evental” research. As suggested by the title, in visualizing the future of event 
studies, we hope to make not only a theoretical and methodological contribution but also to inspire a new wave of visual research.

\section{Situating Visual Research in the Wider Social Sciences}

Although, as previously highlighted by Rakić and Chambers (2010), over the past few decades visual research methods have witnessed a dramatic rise in popularity across the social sciences, it is only relatively recently that the social sciences have experienced a "visual" or a "pictorial" turn (e.g., Jay, 2002; Mitchell, 1994; Pauwels, 2000), with distinct "visual" subdisciplines developing in both sociology and anthropology, and calls being made for further improvements in the overall "visual scientific literacy” (Pauwels, 2000, p. 7). In sociology, for example, Harper (1989, as cited in Rakić \& Chambers, 2010) noted that:

\begin{abstract}
Visual sociology, after contributing to several studies in the early decades of American sociology, disappeared to reemerge in the 1960s. . . . Visual sociology [the use of photographs, film and video to study society and the study of visual artefacts of a society], with increasing organizational success and emerging electronic aids, [now] appears to be on the verge of greater recognition and use within mainstream sociology. (p. 380)
\end{abstract}

Despite the fact that visual aspects of research were incorporated in both early sociology and anthropology, there were also numerous critics of early visual anthropology and sociology, who questioned methodological rigor in the use of the visual (Prosser \& Loxley, 2008; Schnettler, 2013). Some went as far as to claim that such studies undermined the integrity of their discipline (Statz, 1979, as cited in Prosser \& Loxley, 2008). In anthropology, for instance, researcher-produced photography was one of the key fieldwork methods of mid-19th century anthropology with the popularity of this method within anthropological fieldwork diminishing shortly thereafter (Morphy \& Banks, 1997, as cited in Rakić \& Chambers, 2010), the reliance on the visual in anthropology had diminished shortly thereafter. Consequently, the discipline of anthropology until the Second World War was marked by a move towards oral traditions and almost exclusively written anthropological science (Morphy \& Banks, 1997, as cited in Rakić \& Chambers, 2010). Similarly, in the context of geography, Crang (2010) noted that:

\begin{abstract}
"Visual methods" may almost have been killed off before they were born in qualitative geography by powerful arguments about the problematic elements of visual knowledge-and in geography especially. A variety of visual methods, and especially the long reliance on modes of observational practice in landscape work and visual tropes for truth and knowledge across the discipline, have been criticised for assumptions of detachment and objectivity of knower leading to objectification of the known. Recently the issue of representational knowledge has been challenged-and the visual seems perhaps inescapably bound to the representational. (pp. 208-209)
\end{abstract}

Therefore, it is not surprising that visual methods were almost entirely abandoned for quite some time, before a renewed interest in the visual would be observed. Although visual methods are currently on the rise across the social sciences, as evident in the wide range of texts dedicated to visual methodologies (e.g., Banks, 2001, 2007; Banks \& Morphy, 1997; Banks \& Zeitlyn, 2015; Mannay, 2015; Margolis \& Pauwels, 2011; Pink, 2013; Prosser, 1998; Rose, 2016; Stanczak, 2007; van Leeuwen \& Jewitt, 2001; Watt \& Wakefield, 2017), according to Pink (2004), it was only recently that anthropologists have argued for a "(re)integration of the visual into mainstream anthropology and the incorporation of the anthropological aims in ethnographic filmmaking” (as cited in Rakić \& Chambers, 2010, p. 166). Atkinson (2005) took this notion further by arguing "that 'visual' anthropology and sociology should not be treated as separate genres" (section 4, para. 1). Reflecting on the current status of visual methods in social sciences and highlighting the currently widespread acceptance and legitimacy of visual methods, Banks and Zeitlyn (2015) noted that "visual research in social sciences seems in quite good shape" (p. 163), despite claims of poor recognition by peers. In this context, the call for visualizing event studies and the need for critical event visualities (Pernecky \& Rakić, 2019) is part of a new wave of scholarship that sees the importance of visual methods in events research.

It is valuable to briefly reflect on the history and tensions of visual research, because the relationship 
between sociology, anthropology, and imagery has not been an easy one (Prosser \& Loxley, 2008). The list of the most pertinent issues includes: debates around methodological rigor (e.g., Atkinson, 2005); disputes and misunderstandings between proponents of realist and relativist ontologies (e.g., discussions in Rakić, 2012; Rakić \& Chambers, 2009)including tensions surrounding objectivist and subjectivist epistemological positions (e.g., discussions in Loizos, 1997; Morphy \& Banks, 1997; among others); visual research ethics (e.g., Wiles et al., 2008; Wiles, Clark, \& Prosser, 2011; Wiles, Coffey, Robinson, \& Prosser, 2012); and the inevitable polysemy of meanings that comes with visual data (Prosser \& Loxley, 2008). With regard to philosophical matters and the question of whether visuals capture reality or represent context-specific experiences that have been lived and recorded by individuals, scholars must ultimately seek alignment with their philosophical stance. The way in which visual material can be used ranges from "evidence" of reality to "representations" of multiple realities-typically seen in critical theory and social constructionist approaches (Rakić, 2012). The take-away message for events scholars is that, to avoid unnecessary misunderstandings and outdated quarrels between various scholarly camps, one needs to stand on firm philosophical and theoretical footing (Pernecky, 2016b; Pernecky \& Rakić, 2019).

It is worth emphasizing that it is possible to employ visual methods within a variety of epistemological and ontological positions and across the quantitative, mixed, and qualitative spectrum of methodologies. Nevertheless, visual methods tend to be more commonly accepted as legitimate research tools by academics with antiobjectivist and critical stances (and fall within the qualitative methodological traditions), as opposed to the proponents of objectivism. These variations stem largely from the fact that the first (antiobjectivists) value the inevitable polysemy of visual material, which can be interpreted differently by different people. Importantly, this plurality of meanings allows for multiple voices to be heard and made visible-a necessary aim in critical research that is at once philosophical and political. As a result, the question of legitimacy of visual methods is not to be settled by simplistic arguments and the long quantitative-qualitative divide, because what is at stake for one scholar is not what may be at stake for another.

In summary, what is important to recognize is that the aforementioned epistemological tensions have inevitably informed the perceived legitimacy of visual methods. The increased acceptance of subjectivist, intersubjectivist, social constructionist, critical, reflexive, and participatory approaches within social sciences has, along with the technological advances, led to a renewed interest in visual methods. With this crude overview in place, it should be easier for events researchers to appreciate the fluctuation in both popularity and acceptance of visual methods across various disciplines and fields of studies, and to embrace the potential that visual methods have to offer.

\section{Visual (Event) Studies in Practice}

\section{Designing a Visual Event Research Project}

Faced with an intellectual curiosity about a particular theme or research question and pondering the necessity to rely on text- and number-based methods, event scholars have limited visual event literature to turn to for inspiration (e.g., Zuev, 2016). In addition, empirical articles that have utilized visual methodologies in event studies are not only scarce and narrow in range but the term "event" is also ascribed different meanings in both the everyday life and in scholarly research (Pernecky, 2016a; Pernecky \& Rakić, 2019). Therefore, in establishing a frame of reference in this context some researchers might wish to draw on a combination of a wider social science and events literature.

Having established a frame of reference, the researcher then ought to consider the needs of her/ his research project, and at this stage, one must ponder the potential benefits of, or the actual necessity to, include either: (1) visual data from secondary sources or (2) visual data produced as a part of the project, which can subsequently be used for the purposes of analysis, elicitation, and/or creating visual research outputs (see also Rakić \& Chambers, 2012b) Thereafter, the details of the actual research project need to be planned and reflected on: from the research aim and focus (research questions/ hypotheses); the research setting; the philosophical 
and theoretical underpinnings; to the (inter-/multi-/ cross-/postdisciplinary foundation(s); match between visual and any other number- or text-based methods included in the project; the skillset of the researcher(s); and potential ethical considerations and dilemmas (see also discussions in Rakić 2010).

While bearing in mind that visual methods are rarely "purely visual” (Pink, 2013, p. 33) and approaching this discussion in a nonprescriptive manner (e.g., Pink, 2013; Rakić \& Chambers, 2012a), we now turn our attention to what can be described as three core groups of visual methods in event studies: (1) the collection of visual data for the purposes of analysis; (2) the creation of visual data as part of a research project; and (3) elicitation techniques and similar alternatives (adapted from Rakić \& Chambers, 2012b).

\section{Collecting Visual Data for the Purpose of Analysis}

As highlighted in our discussion of visual echoes of events (Pernecky \& Rakić, 2019), there is an immense range of visual data from secondary sources that can be collected for the purpose of analysis. Confronted with such a wide variety of sources, event scholars and students may wonder about the practicalities of sourcing or capturing the required data, as well as methodological implications. For instance, with the popularity of social media and readily available digital content, questions arise about the size of the data set, quality, and representativeness. In other words: how much visual material do we need to include? How do we judge its quality? Is it representative? Additional conundrums may include the time frame suitable for collecting visual material-a less of an issue in case-study research but a vital decision in longitudinal studies. Hence, as part of the initial scoping, there are a number of considerations that will determine the overall shape of the project. Although we are constrained here from offering a definite and complete guide, what follows is some guidance researchers may find useful.

In terms of the collection of data from secondary sources, and in the context of tourism studies (and data such as brochures, postcards, stamps, the Internet, and photographs), Jokela and Raento (2012) advised that the overall aim needs to be the creation of a data set that contains a "manageable, reliable and representative sample” (p. 54), which is also fit for its purpose. This effectively means that the data set needs to be manageable for the researcher(s) to analyze via their chosen approach to data analysis (more on this later), and importantly, that this analysis will assist the researcher(s) in answering their research questions. Whereas the matter of the "representativeness" of data is of greater significance within quantitative studies, all visual researchers ought to approach the data collection stage with a meaningful, logical, and thought-through process. For example, visual research underpinned by critical theory may draw on fewer images that clearly depict the point or an issue investigated by the researcher. In contrast, a study that seeks to capture the "generic" mood at a specific event will require a much larger number of visual materials. Further guidance on quantitative approaches, in this particular case quantitative content analysis as applied on a data set of journalistic images of the 2007 G8 summit, is offered in Bock, Isermann, and Knieper (2011).

As far as the actual "collection" or "capturing" of data is concerned, there is an important step that can later jeopardize the planned publications based on a project: most secondary materials require copyright permissions in order to be reproduced as figures within research outputs. This extends to digital copies of posters that may be used for the purposes of semiotic analyses (Sel \& Aktas, 2019) and also screenshots of social media (Porter, 2019). Presuming that the necessary data has been gathered, generally speaking, there are three types of analyses that have enjoyed popularity in visual research. These include semiotic, discourse, and content analyses (for a deeper insight into these and also other types of analyses, see Rose, 2016; van Leeuwen \& Jewitt, 2001). The chosen method of analysis needs to be suitable in terms of actually assisting the researcher(s) to meet the project aim and objectives, and to correspond with the philosophical and theoretical assumptions underpinning the project. For example, works motivated by objectivism may incorporate a computer-assisted, quantitative content analysis of large visual data sets in order to produce generalizable findings. In comparison, projects informed by critical theory may draw on in-depth discourse analyses of a smaller data set that nonetheless offers both a 
meaningful interpretation of the data and representation of the study context. Depending on the research aim, the latter may be more suitable, say, in producing in-depth, emancipatory knowledge. That said, it is important to remember that visual data will often include textual (or audio) elements and including the textual (or audio) elements may be necessary, given that viewers of these materials (e.g., potential event attendees seeing a poster) will also rely on both the image and the text in interpreting its meaning.

Last but not least, an important decision concerns which visual material from the data set should be included in the discussion of findings, and in that regard, most visual researcher(s) will include typical examples of visual materials as figures within the discussion of their project findings. However, dilemmas additional to the copyright permissions mentioned earlier might in some cases also come to the fore for the researcher or even the editor. An example of such a situation includes the decision taken by both a book chapter author and the book editors not to include the billboard posters of Switzerland's (far) right-wing political party SVP, which were the object of critical analysis in a chapter on right-wing visual rhetoric (Feighery, 2015) given that it this case it was deemed neither ethical nor "appropriate to contribute to further proliferation of the[se]" (Chambers \& Rakić, 2015, p. 10; text in brackets added).

\section{Creating Visual Data as a Part of a Research Project}

Some research projects, and particularly those that happen to focus on what we have termed "actual event visualities” (Pernecky \& Rakić, 2019), might not only be fertile ground for the production of visual data as a part of the project by either the researcher and/or their research participants, but the study of these visualities might necessitate the production of visual data as a part of the project. For example, studying picturing practices or performative aspects of event attendance is likely to prove impossible without the inclusion of either researcher-produced or attendees' own visuals (e.g., in the form of photography, video, drawings, or mapping practices). On this note, the cultural geographies scholar Crang (2003) reflexively noted: "here I am: taking pictures of people taking pictures; showing pictures of making pictures; the students watching me; watching the tourists" (p. 242). Some event projects may necessitate a similar kind of researcher-produced photography and/or videos that are later used as data for the purposes of analysis, teaching, and dissemination of findings from a research project.

Although a wide variety of visuals such as photographs, videos, and drawings can be created in the field for the purposes of analysis and later used in the creation of visual research outputs (e.g., documentaries, videos, and exhibitions), they can also result in a wider engagement with audiences beyond academia (e.g., discussions in Rakić, 2010; Rakić \& Chambers, 2009, 2010). It is important to bear in mind that the creation of visual data as a part of a research project is likely to involve a significant consideration of ethical issues and dilemmas. For example, in embarking on visual ethnographic fieldwork aiming to study the construction of personal and collective identities among attendees at a festival, the researcher is likely to be faced with a number of ethical conundrums, such as:

1. Is photography or video taking common practice at this festival?

2. Is permission to film or photograph neededand from whom?

3. Could (and should) anonymity be offered to research participants who contribute to the project by participating in audio-visually recorded interviews? (adapted from Rakić, 2010).

Many of these dilemmas stem from the fact that (audio)visual recordings allow for little or no anonymity. It is in this regard that the extensive debates surrounding the questions of anonymity, confidentiality, permissions, and other common ethical dilemmas in visual research (e.g., Wiles et al., 2008; Wiles et al., 2011; Wiles et al., 2012) are likely to prove to be invaluable. Namely, existing visual ethics publications can both be referred to in the ethical approval documents written in the design stages of a particular (visual) project, as well as be relied on in informing additional decisions related to research ethics that were not foreseen in the design stages of a project and that might need to considered on an ad hoc basis at the time of the fieldwork. 
Although a number of ethical considerations will need to be made in the context of both planning and conducting research that incorporates researcher or research participant-produced visuals, these also offer numerous opportunities in researching events phenomena. Importantly, some projects might result in the production of both textual research outputs such as a thesis, journal article, or a book chapter, and (audio)visual outputs such as a documentary (e.g., Rakić, 2008a, 2008b). The possibility of producing both research output types-textual and (audio)visual—can be exceptionally rewarding given that (audio)visual research outputs such as documentaries, videos, and exhibitions can enable the researcher to reach, and engage with, wider audiences (Rakić \& Chambers, 2010).

\section{Elicitation Techniques and Similar Alternatives}

Visual material sourced from secondary sources or produced by researchers or their research participants can help elicit richer findings during interviews and focus groups. This is accomplished through reliance on objects such as photographs, videos, and other memorabilia to provide research participants with "greater space for personal interpretations and responses” (Lapenta, 2011, p. 201), as exemplified in the numerous studies in the wider social (e.g., for an overview of photo-elicitation in anthropology and sociology, see Harper, 2002). Although photographs remain the most popular type of (visual) object used for elicitation purposes, souvenirs and other memorabilia can also provide stimuli to help participants recall event experience, memories, emotions, and information (Bremer, 2018). Events researchers may wish to consider the following broad elicitation strategies:

1. Objects are provided by the researcher(s) for the purposes of the interview(s) - including secondary sources such as newspaper articles and photographs from archives;

2. Objects are provided by the research participant(s) for the purposes of the interview(s) - including objects such as personal photographs, drawings, photo albums, souvenirs, postcard collections, etc.; and

3. Objects are produced collaboratively between the researcher(s) and their research participant(s) during the actual research project. (adapted from Lapenta, 2011)

It is worth highlighting that there are currently limited examples of elicitation techniques in events studies, and that there are also early approaches to photo-elicitation, such as Autodriving, Reflexive Photography, and PhotoVoice (Hurworth, 2003, as cited in Lapenta, 2011). Autodriving "indicates that the interview is 'driven' by informants who are seeing and hearing their own behaviour” (Heisly \& Levy, 1991, p. 257); reflexive photography typically entails participants' personal reflection on photographs taken by them (e.g., Amerson \& Livingston, 2014); and PhotoVoice is a community-based participatory image production aimed at creating social change (see PhotoVoice, 2018; Lapenta, 2011). Another related method-Autophotography-is useful in mapping the environment of the research participants, whereby they are asked to capture the world through their own eyes (Glaw, Inder, Kable, \& Hazelton, 2017). This can be particularly valuable in understanding how festivals and events are experienced by different participants, including minority groups and individuals who may struggle to express themselves though verbal and oral means. For instance, people with disabilities may be asked to take photographs at a specific festival to identify the "accessibility" of the event, and therefore provide useful data and information through their embodied and visually-documented experience. Overall, although these methods bear some similarities, they also resemble the subtle nuances of visual methods research-offering interesting opportunities in the domain of events.

Finally, a particularly interesting possibility is to use visual materials to create what Lamond and Ager (this issue) have termed "evental research.” In addition to sourcing or (collaboratively) creating photographs, videos, and other material objects as part of the research process, event scholars may wish to deliberately stage events in order to induce and study participants' reactions.

\section{Conclusion}

In aiming to inspire a new wave of visual event scholarship, this article highlighted the fact that not only have visual methods been accepted as 
legitimate research tools in the wider social sciences, they have also witnessed a dramatic rise in popularity. Given the inherently multisensory and therefore also visual nature of events, visual methods have much to offer to event studies. Similarly, to the arguments made recently in the field of tourism (e.g., see Rakić, 2010; Rakić \& Chambers, 2010; Rakić \& Chambers, 2012b), visual research opens the possibility to create knowledge that would otherwise remain inaccessible. Moreover, visual methods can be an essential tool for obtaining deeper insights, and for producing visual research outputs such as videos, documentaries, and exhibitions. In conclusion, as a wider attempt to visualize the future of event studies, we see research that goes beyond the qualitative/quantitative schisms, and which adds an important, complementary, and at times also creative dimension to event scholarship. In this respect, the selected contributions in this Special Issue highlight the breadth, richness, and diversity that visual approaches have to offer.

\section{References}

Amerson, R., \& Livingston, W. G. (2014). Reflexive photography: An alternative method for documenting the learning process of cultural competence. Journal of Transcultural Nursing, 25(2), 202-210. doi: 10.1177/ 1043659613515719

Atkinson, P. (2005). Qualitative research-unity and diversity. Forum Qualitative Sozialforschung/Forum: Qualitative Social Research, 6(3). Retrieved from http://www. qualitative-research.net/fqs-texte/3-05/05-3-26-e.htm

Banks, M. (2001). Visual methods in social research. London, UK: Sage.

Banks, M. (2007). Using visual data in qualitative research. London, UK: Sage.

Banks, M., \& Morphy, H. (Eds.). (1997). Rethinking visual anthropology. Wiltshire, UK: Yale University Press.

Banks, M., \& Zeitlyn, D. (2015). Visual methods in social research. London, UK: Sage.

Bock, A., Isermann, H., \& Knieper, T. (2011). Quantitative content analysis of the visual. In E. Margolis \& L. Pauwels (Eds.), The SAGE handbook of visual methods (pp. 265282). London, UK: Sage.

Bremer, J. S. (2018). The significance of souvenirs in contemporary music festivals: The case of the Hurricane Festival, Scheeßel, Germany. Unpublished Masters’ thesis, University of Brighton, Brighton, UK.

Chambers, D., \& Rakić, T. (2015). Tourism research frontiers: An introduction. In D. Chambers \& T. Rakić (Eds.), Tourism research frontiers: Beyond the boundaries of knowledge (pp. 1-12). Bingley, UK: Emerald.
Crang, M. (2003). The hair in the gate: Visuality and geographical knowledge. Antipode, 35(2), 238-243.

Crang, M. (2010). Visual methods and methodologies. In D. DeLyser, S. Herbert, S. Aitken, M. Crang, \& L. McDowell (Eds.), The SAGE handbook of qualitative geography (pp. 208-224). London, UK: Sage.

Feighery, W. (2015). Right-wing visual rhetoric and Switzerland's tourism image. In D. Chambers \& T. Rakić (Eds.), Tourism research frontiers: Beyond the boundaries of knowledge (pp. 105-122). Bingley, UK: Emerald.

Glaw, X., Inder, K., Kable, A., \& Hazelton, M. (2017). Visual methodologies in qualitative research: Autophotography and photo elicitation applied to mental health research. International Journal of Qualitative Methods, 16(1), doi: 10.1177/1609406917748215

Harper, D. (1989). Visual sociology: Expanding the sociological vision. In G. Blank, J. McCartney, \& E. Brent (Eds.), New technologies in sociology: Practical applications in research and work (pp. 81-112). New Brunswick, NJ: Transaction Publishers.

Harper, D. (2002). Talking about pictures: A case for photoelicitation. Visual Studies, 17(1), 13-26.

Heisley, D. D., \& Levy, S. J. (1991). Autodriving: A photoelicitation technique. Journal of Consumer Research, 18(3), 257-272. doi: 10.1086/209258

Jay, M. (2002). Cultural relativism and the visual turn. Journal of Visual Culture, 1(3), 265-278.

Jokela, S., \& Raento, P. (2012). Collecting visual materials from secondary sources. In T. Rakić \& D. Chambers (Eds.), An introduction to visual research methods in tourism (pp. 53-69). London, UK: Routledge.

Lapenta, F. (2011). Some theoretical and methodological views on photo-elicitation. In E. Margolis \& L. Pauwels (Eds.), The SAGE handbook of visual research methods (pp. 201-213). London, UK: Sage.

Loizos, P. (1997). First exits from observational realism: Narrative experiments in recent ethnographic films. In M. Banks \& H. Morphy (Eds.), Rethinking visual anthropology (pp. 81-104). New Haven, CT: Yale University Press.

Mannay, D. (2015). Visual, narrative and creative research methods: Application, reflection and ethics. London, UK: Routledge.

Margolis, E., \& Pauwels, L. (Eds.). (2011). The SAGE handbook of visual research methods. London, UK: Sage.

Mitchell, W. J. T. (1994). Picture theory: Essays on verbal and visual representation. Chicago, IL: University of Chicago Press.

Morphy, H., \& Banks, M. (1997). Introduction: Rethinking visual anthropology. In M. Banks \& H. Morphy (Eds.), Rethinking visual anthropology (pp. 1-35). New Haven, CT: Yale University Press.

Pauwels, L. (2000). Taking the visual turn in research and scholarly communication. Visual Sociology, 15, 7-14.

Pernecky, T. (Ed.). (2016a). Approaches and methods in event studies. London, UK: Routledge. 
Pernecky, T. (2016b). Epistemic foundations of event studies. In T. Pernecky (Ed.), Approaches and methods in event studies (pp. 3-21). London, UK: Routledge.

PhotoVoice. (2018). Reframing the world. Retrieved from https://photovoice.org

Pink, S. (2004). Conversing anthropologically: Hypermedia as anthropological text. In S. Pink, L. Kürti, \& A. L. Afonso (Eds.), Working images: Visual research and representation in ethnography (pp. 166-184). London, UK: Routledge.

Pink, S. (2013). Doing visual ethnography (3rd ed.). London, UK: Sage.

Prosser, J. (Ed.). (1998). Image-based research: A sourcebook for qualitative researchers. London, UK: Falmer Press.

Prosser, J., \& Loxley, A. (2008). ESRC National Centre for Research Methods review paper: Introducing visual methods. Retrieved from http://eprints.ncrm.ac.uk/420/1/ MethodsReviewPaperNCRM-010.pdf

Rakić, T. (2008a). World heritage, tourism and national identity: A case study of the Acropolis in Athens, Greece. Ph.D. thesis, Edinburgh Napier University, Edinburgh, Scotland.

Rakić, T. (Director). (2008b). Visiting the Athenian Acropolis. UK and Greece: PitchDarkProductions [ethnographic documentary].

Rakić, T. (2010). Tales from the field: Video and its potential for creating cultural tourism knowledge. In G. Richards \& W. Munsters (Eds.), New perspectives on cultural tourism research (pp. 129-140). Wallingford, UK: CABI.

Rakić, T. (2012). Philosophies of the visual (method) in tourism research. In T. Rakić \& D. Chambers (Eds.), An introduction to visual research methods in tourism (pp. 17-32). London, UK: Routledge.

Rakić, T., \& Chambers, D. (2009). Researcher with a movie camera: Visual ethnography in the field. Current Issues in Tourism, 12(3), 255-270.
Rakić, T., \& Chambers, D. (2010). Innovative techniques in tourism research: An exploration of visual methods and academic filmmaking. International Journal of Tourism Research, 12(4), 379-389.

Rakić, T., \& Chambers, D. (Eds.). (2012a). An introduction to visual research methods in tourism. London, UK: Routledge.

Rakić, T., \& Chambers, D. (2012b). Introducing visual methods to tourism studies. In T. Rakić \& D. Chambers (Eds.), An introduction to visual research methods in tourism studies (pp. 3-14). London, UK: Routledge.

Rose, G. (2016). Visual methodologies: An introduction to researching with visual materials (4th ed.). London, UK: Sage.

Schnettler, B. (2013). Notes on the history and development of visual research methods. InterDisciplines, 1, 41-75.

Stanczak, G. C. (Ed.). (2007). Visual research methods: Image, society and representation. London, UK: Sage.

van Leeuwen, T., \& Jewitt, C. (Eds.). (2001). Handbook of visual analysis. London, UK: Sage.

Watt, S., \& Wakefield, C. (2017). Teaching visual methods in the social sciences. London, UK: Routledge.

Wiles, R., Clark, A., \& Prosser, J. (2011). Visual research ethics at the crossroads. In E. Margolis \& L. Pauwels (Eds.), The SAGE handbook of visual research methods (pp. 685-706). London, UK: Sage.

Wiles, R., Coffey, A., Robinson, J., \& Prosser, J. (2012). Ethical regulation and visual methods: Making visual research impossible or developing good practice? Sociological Research Online, 17(1), 1-10.

Wiles, R., Prosser, J., Bagnoli, A., Clark, A., Davies, K., Holland, S., \& Renold, E. (2008). Visual ethics: Ethical issues in visual research. Retrieved from http://eprints. ncrm.ac.uk/421/1/MethodsReviewPaperNCRM-011.pdf

Zuev, D. (2016). Visual methods in event studies. In T. Pernecky (Ed.), Approaches and methods in event studies (pp. 96-119). London, UK: Routledge. 